\title{
Right Ventricular Assist Device
}

National Cancer Institute

\section{Source}

National Cancer Institute. Right Ventricular Assist Device. NCI Thesaurus. Code C80472.

A mechanical pump which also includes a control system and an energy supply. It receives blood from the right ventricle and delivers it to the pulmonary artery, thus helping the heart to pump sufficient blood to the body. 